\title{
GESNERIACEAE NO PARQUE ESTADUAL DA SERRA DO PAPAGAIO, MINAS GERAIS, BRASIL
}

\author{
LUCIANA CARVALHO PEREIRA*, ALAIN CHAUTEMS ${ }_{* * * * *}^{* *}$ RODIGO DE MACÊDO MELLO ${ }^{* *}$ \& \\ LUIZ MENINI NETO ${ }^{*, * * *}$
}

\author{
* Centro de Ensino Superior de Juiz de Fora, Campus Arnaldo Jannsen, Luz Interior, 100, Santa Luzia, \\ 36030-776 - Juiz de Fora, Minas Gerais, Brasil; e-mail: lucianabae@yahoo.com.br. \\ ${ }^{* *}$ Conservatoire et Jardin Botaniques de la Ville de Genève, Ch. de l'Impératrice 1, \\ C.P. $60, \mathrm{CH}-1292$ - Chambésy, Suíça. \\ *** Universidade Federal de Juiz de Fora, ICB, s.n., Martelos, 36036-330 - Juiz de Fora,
} Minas Gerais, Brasil.

\begin{abstract}
Gesneriaceae in the Parque Estadual da Serra do Papagaio, Minas Gerais, Brazil). The Parque Estadual da Serra do Papagaio is located in the Mantiqueira Range, in Southern Minas Gerais. It harbors an important remnant of Atlantic Forest with mixed formation of high altitude grasslands, dense rainforest and areas with mixed ombrophilous forest, distributed in an area of 22.917 hectares, of which about $50 \%$ has steep slopes and altitude above $1.800 \mathrm{~m}$. Gesneriaceae is represented in the Park by eight species belonging to the genera Nematanthus (N. fornix (Vell.) Chautems), Seemannia (S. sylvatica (Kunth) Hanst) and Sinningia ( $S$. aggregata (Ker Gawl.) Wiehler, S. allagophylla (Mart.) Wiehler, S. cooperi (Paxton) Wiehler, S. douglasii (Lindl) Chautems, S. gigantifolia Chautems, S. magnifica (Otto \& A. Dietr.) Wiehler). Identification key, morphological descriptions, illustrations and comments about ecology, taxonomy and geographic distribution of the species are provided.
\end{abstract}

Key-words: Atlantic Forest, Nematanthus, Serra da Mantiqueira, Seemannia, Sinningia.

Resumo - (Gesneriaceae no Parque Estadual da Serra do Papagaio, Minas Gerais, Brasil). O Parque Estadual da Serra do Papagaio está localizado na Serra da Mantiqueira, sul de Minas Gerais. Abriga um importante remanescente de Floresta Atlântica, possuindo formação mista de campos de altitude, floresta ombrófila densa e áreas de enclave com floresta ombrófila mista distribuída em uma área de 22.917 hectares, dos quais cerca de $50 \%$ apresenta declividade acentuada e altitudes acima de $1.800 \mathrm{~m}$. Gesneriaceae está representada no Parque por oito espécies, pertencentes aos gêneros Nematanthus ( $N$. fornix (Vell.) Chautems), Seemannia ( $S$. sylvatica (Kunth) Hanst) and Sinningia (S. aggregata (Ker Gawl.) Wiehler, S. allagophylla (Mart.) Wiehler, $S$. cooperi (Paxton) Wiehler, S. douglasii (Lindl) Chautems, S. gigantifolia Chautems, S. magnifica (Otto \& A.Dietr.) Wiehler). São apresentadas chave de identificação, descrições morfológicas, ilustrações, comentários ecológicos, taxonômicos e de distribuição geográfica das espécies.

Palavras chave: Floresta Atlântica, Nematanthus, Serra da Mantiqueira, Seemannia, Sinningia.

\section{Introdução}

Gesneriaceae se distribui pela zona pantropical e, mais raramente, em zona temperada. Inclui entre 3000 e 3700 espécies, subordinadas a 135-150 gêneros pertencentes a duas subfamílias, Gesnerioideae, exclusiva da região Neotropical, e Cyrtrandoideae, com distribuição pela África, Ásia, Austrália e Ilhas do Pacífico (Burtt \& Wiehler 1995; Weber 2004).

O Brasil constitui um centro secundário de diversidade de espécies de Gesneriaceae, tendo aproximadamente 28 gêneros, englobando ca. 215 espécies, dos quais dois terços encontram-se nas regiões extra-amazônicas, com importante concentração e forte endemismo na Região Sudeste, habitando principalmente a Floresta Atlântica (Chautems 1991, Araújo \& Chautems 2012).

A Serra da Mantiqueira localiza-se entre os estados de Minas Gerais, São Paulo, Rio de Janeiro e Espírito Santo. Em um dos trechos de maior altitude, denominado Terras Altas da Mantiqueira, existem duas importantes Unidades de Conservação, o maciço do Itatiaia, protegido como Parque Nacional desde 1937 (entre os estados do Rio de Janeiro e Minas Gerais) e o Parque Estadual da Serra do Papagaio (PESP), criado em 1998 (Executivo/MG 1998, Gonçalves 2003), que apresenta um mosaico vegetacional representado por áreas campestres e florestais (Costa 1994).

O conhecimento da biodiversidade dos ecossistemas, através de levantamentos florísticos, é importante como embasamento para a conservação ambiental, bem como para uma potencial exploração racional dos recursos e das áreas naturais ainda existentes. Esses fatores ressaltam a necessidade do conhecimento da diversidade biológica existente no PESP, como subsídio para manejo e conservação da área, uma vez que nenhum estudo sistemático de sua flora foi realizado até o momento.

Assim sendo, os objetivos deste trabalho foram: inventariar as espécies de Gesneriaceae ocorrentes no PESP, de maneira a ampliar o conhecimento florístico e contribuir com o plano de manejo do Parque e o enriquecimento do conhecimento da flora do estado de Minas Gerais, além da ampliação do conhecimento da taxonomia e distribuição geográfica das espécies e da família como um todo. 


\section{Material e métodos}

Área de estudo - O Parque Estadual da Serra do Papagaio (PESP) foi criado pelo Decreto $n^{\circ} 39.793$ em 5 de agosto de 1998 e está localizado na Serra da Mantiqueira, no sul de Minas Gerais (Fig. 1), abrangendo 22.197 hectares dos municípios de Aiuruoca, Alagoa, Baependi, Itamonte e Pouso Alto (Executivo/MG 1998).

Abriga um conjunto variado de subsistemas da Floresta Atlântica, que diferem entre si conforme 0 solo, a temperatura e o rigor dos ventos e das chuvas. Encontra-se um mosaico vegetacional representado por florestas ombrófilas densas, florestas nebulares a partir de $1.000 \mathrm{~m}$ de altitude, além de florestas de araucária (floresta ombrófila mista) a partir dos $1.600 \mathrm{~m}$, com destaque para a ocorrência das gimnospermas Araucaria angustifolia (Bertol) Kuntze (Araucariaceae) e Podocarpus lambertii Klotzsch ex Endl. (Podocarpaceae). Acima de $2.000 \mathrm{~m}$ a vegetação torna-se herbáceo-arbustiva, os arbustos ficam mais espaçados conforme a altitude aumenta, até que ocorra predominância de gramíneas, liquens e musgos, nos campos de altitude (Costa 1994; Executivo/MG 1998; IEF/MG 2010).

$O$ Parque interliga-se geograficamente com a porção norte do Parque Nacional do Itatiaia, permitindo uma proteção mais efetiva da flora e da fauna, por compor um conjunto montanhoso contínuo, legalmente preservado. No Parque do Papagaio, encontram-se conjuntos montanhosos das Serras do Garrafão e do Papagaio, apresentando cerca de 50\% da área com declividade acentuada e altitude acima de $1.800 \mathrm{~m}$. As encostas mais elevadas localizam-se no sul (Morro da Mitra do Bispo com 2.149m) e no sudoeste (Pico da Bandeira com $2.357 \mathrm{~m}$ na Serra do Papagaio). Situa-se em uma área de rochas ígneas ácidas, representadas por granitos de granulação fina a grosseira (IEF/MG 2010).

$\mathrm{Na}$ região estão localizadas as nascentes dos principais cursos d'água formadores da Bacia do Rio Grande, responsável pelo abastecimento dos principais municípios da Mesorregião Sul de Minas Gerais (IEF/MG 2010).

Trabalho de campo e laboratório - O levantamento das Gesneriaceae no Parque Estadual da Serra do Papagaio foi realizado através de coletas mensais específicas para a família, em caminhadas aleatórias percorrendo áreas da UC, no período de 12 meses, entre outubro de 2009 e setembro de 2010, complementado por coletas esporádicas em 2011 e coletas sistemáticas para estudo da flora do Parque entre março de 2012 e março de 2013. Exemplares férteis foram coletados, sendo realizadas anotações em campo dos dados pertinentes à identificação das espécies, como: habitat, altura do individuo, coloração de flores e folhas, viscosidade, odor, localização, entre outros que poderiam se perder no processo de herborização, assim como também foram feitas fotos de cada espécie coletada e do ambiente em seu entorno.
Após o procedimento realizado em campo, os materiais foram herborizados segundo metodologia usual (Fidalgo \& Bononi 1989) e depositados no Herbário Leopoldo Krieger (CESJ) da Universidade Federal de Juiz de Fora (acrônimo segundo Thiers 2012).

A identificação foi realizada através de comparações com material do acervo do Herbário CESJ e auxílio de bibliografia específica. Além dos exemplares coletados durante este estudo, foram analisadas também coletas anteriores realizadas no PESP durante a elaboração do plano de manejo, depositadas no Herbário da Universidade Federal de Minas Gerais (BHCB), Museu Nacional do Rio de Janeiro $(R)$ e o herbário do Jardim Botânico do Rio de Janeiro (RB).

\section{Resultados e discussão}

Oito espécies de Gesneriaceae foram registradas no PESP, distribuídas em três gêneros: Nematanthus e Seemannia com apenas uma espécie cada e Sinningia, representado por seis espécies.

Dentre as espécies coletadas no PESP, três são de hábito epifítico (Sinningia cooperi (Paxton) Wiehler, S. douglasii (Lindl.) Chautems e Nematanthus fornix (Vell.) Chautems (que pode ser tanto epífita quanto terrícola), três são rupícolas ( $S$. aggregata (Ker Gawl.) Wiehler, S. gigantifolia Chautems e $S$. magnifica (Otto \& A. Dietr.) Wiehler), e duas são terrícolas (Seemannia sylvatica (Kunth) Hanst. e Sinningia allagophylla (Mart.) Wiehler). Estes dados complementam aqueles obtidos durante as coletas realizadas para elaboração do plano de manejo do PESP por Silva et al. (2008), onde foram citadas apenas quatro espécies de Gesneriaceae: Sinningia allagophylla, S. cooperi, S. gigantifolia e S. magnifica.

A representatividade do gênero Sinningia no PESP se justifica por ser um dos mais ricos da família, bem como o mais rico na flora nativa, com distribuição exclusiva na região Neotropical, concentrada, sobretudo, na Floresta Atlântica, onde ocorrem 64 das 67 espécies conhecidas para o Brasil (Araújo \& Chautems 2012). Assim, freqüentemente Sinningia também é predominante entre as Gesneriaceae em outras áreas estudadas em Minas Gerais e estados limítrofes (Araújo et al. 2005; Leoni et al. 2005; Alves et al. 2009, Barros et al. 2010, Blaser et al. 2011). No entanto a proporção encontrada no PESP em relação ao número total de espécies de Gesneriaceae registradas só é superada pela Serra da Pedra Branca, onde todas as cinco espécies ocorrentes pertencem a Sinningia (Rezende 2010).

A riqueza de Gesneriaceae do PESP mostrase intermediária quando comparada com outros estudos realizados em áreas predominantemente campestres no estado de Minas Gerais (Tab. 1). No entanto, nesta comparação não foi considerada a Cadeia do Espinhaço completa, no estado de Minas Gerais, onde foram registradas 21 espécies (Araújo et al. 2005), devido à extensão muito superior a de qualquer outra das áreas consideradas, além de englobar a Serra do Cipó, representada pelo estudo de Araújo et al. (2004). 
Gesneriaceae no Parque Estadual da Serra do Papagaio, Minas Gerais, Brasil

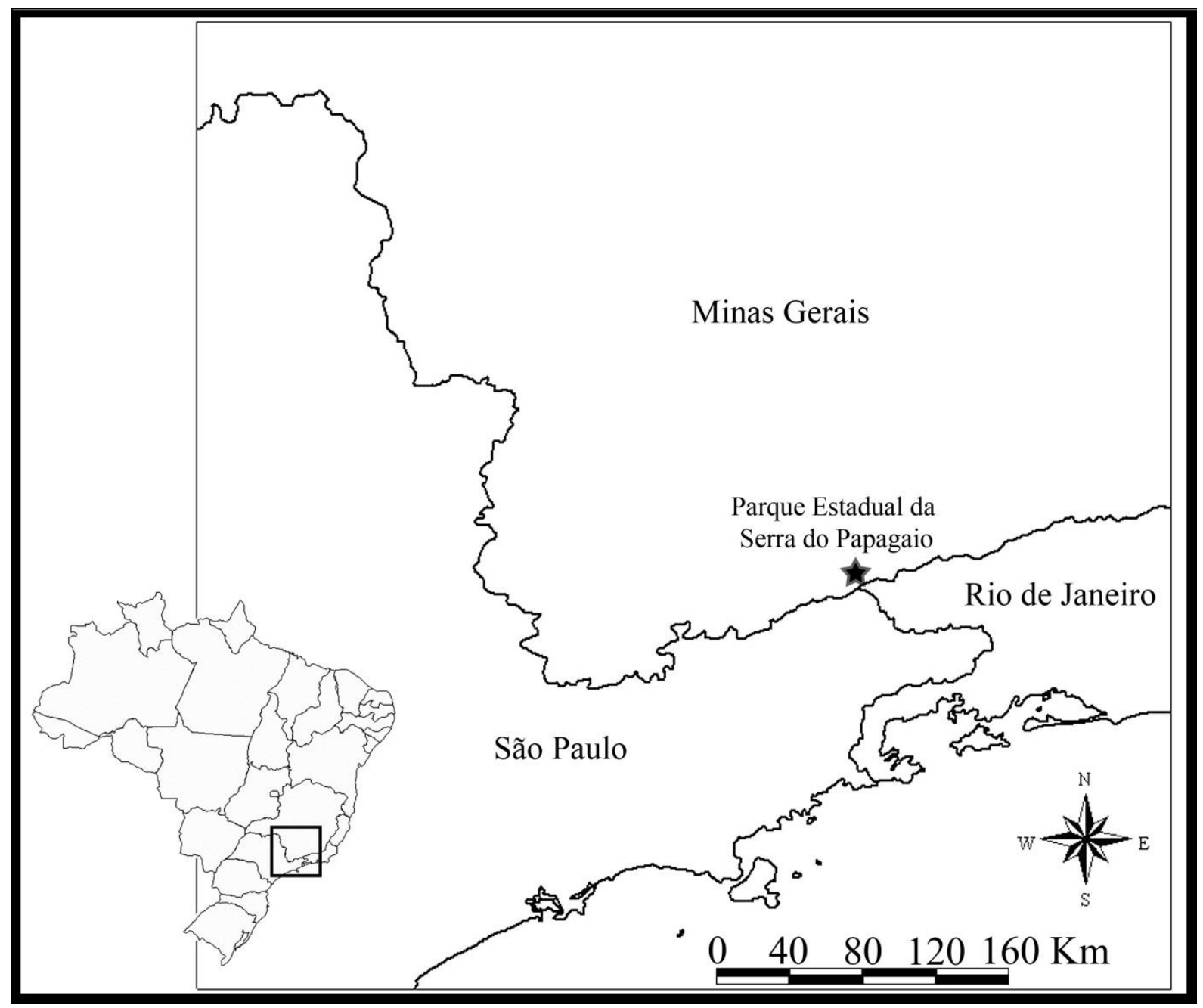

Fig. 1 - Localização do Parque Estadual da Serra do Papagaio, Minas Gerais. 
L. C. Pereira et al.

Dentre as espécies registradas no PESP, apenas $S$. sylvatica não foi encontrada em nenhuma das áreas supracitadas (Tab. 1), enquanto Sinningia douglasii e $S$. gigantifolia ocorrem em apenas outras duas áreas e Nematanthus fornix somente em uma das outras áreas. As demais espécies são de ocorrência relativamente comum entre as áreas com vegetação de altitude, destacando-se Sinningia magnifica encontrada em sete das nove áreas comparadas e $S$. allagophylla registrada em seis.
De acordo com Chautems (2007), S. gigantifolia é a única espécie do gênero que apresenta folhas de grande porte e a base do caule perene, além do tubérculo que pode alcançar grandes dimensões. Nas outras espécies do gênero, somente o tubérculo é perene e rebrota anualmente produzindo um caule que degenera após a floração. É também a única espécie de Sinningia encontrada no PESP que foi observada tanto em ambiente de floresta quanto nos campos de altitude.

Tabela 1 - Comparação de ocorrência das espécies de Gesneriaceae registradas no Parque Estadual da Serra do Papagaio com outras áreas predominantemente campestres no estado de Minas Gerais (MG) e estados limítrofes, Espírito Santo (ES) e Rio de Janeiro (RJ).

\begin{tabular}{|c|c|c|c|c|c|c|c|c|c|}
\hline & $\begin{array}{l}\text { PESP } \\
\text { (MG) }\end{array}$ & $\begin{array}{c}\mathrm{PNC} \\
(\mathrm{MG} / \mathrm{ES})\end{array}$ & $\begin{array}{l}\text { PESB } \\
\text { (MG) }\end{array}$ & $\begin{array}{c}\mathrm{SC} \\
(\mathrm{MG})\end{array}$ & $\begin{array}{l}\text { SSJ } \\
\text { (MG) }\end{array}$ & $\begin{array}{l}\text { SPB } \\
(\mathrm{MG})\end{array}$ & $\begin{array}{c}\mathrm{PEI} \\
\text { (MG) }\end{array}$ & $\begin{array}{c}\mathrm{SN} \\
(\mathrm{MG})\end{array}$ & $\begin{array}{c}\mathrm{PNI} \\
\text { (MG/RJ) }\end{array}$ \\
\hline $\begin{array}{l}\text { Gêneros/ } \\
\text { Espécies }\end{array}$ & $3 / 8$ & $6 / 13$ & $5 / 14$ & $5 / 9$ & $4 / 8$ & $1 / 5$ & $3 / 7$ & $4 / 9$ & $3 / 9$ \\
\hline Área (ha) & 22000 & 26000 & 13210 & 100000 & - & - & 1488 & 10000 & 30000 \\
\hline Fontes & 1 & 2 & 3 & 4 & 5 & 6 & 7 & 8 & 9 \\
\hline $\begin{array}{l}\text { Nematanthu } \\
\text { s fornix } \\
\text { Seemannia } \\
\text { sylvatica }\end{array}$ & $x$ & & & & & & & & X \\
\hline $\begin{array}{l}\text { Sinningia } \\
\text { aggregata }\end{array}$ & $X$ & & & & X & $x$ & & & X \\
\hline $\begin{array}{l}\text { Sinningia } \\
\text { allagophylla }\end{array}$ & $X$ & $X$ & & $X$ & & X & $X$ & & $X$ \\
\hline $\begin{array}{l}\text { Sinningia } \\
\text { cooperi }\end{array}$ & $X$ & $X$ & $X$ & & & $X$ & $X$ & $x$ & \\
\hline $\begin{array}{l}\text { Sinningia } \\
\text { douglasii }\end{array}$ & $x$ & & & & $x$ & & & & \\
\hline $\begin{array}{l}\text { Sinningia } \\
\text { gigantifolia }\end{array}$ & $x$ & & $X$ & & & $X$ & & & X \\
\hline $\begin{array}{l}\text { Sinningia } \\
\text { magnifica }\end{array}$ & X & $x$ & $x$ & $x$ & $x$ & $x$ & & & X \\
\hline
\end{tabular}

Abreviações: PESP - Parque Estadual da Serra do Papagaio; PNC - Parque Nacional do Caparaó; PESB - Parque Estadual da Serra do Brigadeiro; SC - Serra do Cipó; SSJ - Serra de São José; SPB - Serra da Pedra Branca; PEI - Parque Estadual de Ibitipoca; SN - Serra Negra; PNI - Parque Nacional do Itatiaia. Fontes: 1) presente estudo; 2) Leoni \& Chautems (2004); 3) Leoni et al. (2005); 4) Araújo et al. (2004); 5) Alves \& Kolbek (2009); 6) Rezende (2010); 7) Blaser et al. (2011); 8) Blaser et al. (2012); 9) Barros et al. (2010).

Gesneriaceae Rich. \& Juss. ex DC., Essai Prop. Méd. PI. ed.2: 192. 1816 ("Gessnerieae"), nom. cons.

Ervas geralmente perenes, subarbustos ou arbustos, terrícolas ou epifíticas (cerca de $20 \%$ das espécies), podendo apresentar estruturas para adaptação às estações secas, na forma de tubérculos ou rizomas; caule aéreo herbáceo ou lenhoso, ereto ou pendente. Folhas simples, oposto-cruzadas, às vezes verticiladas, isófilas ou anisófilas, pecioladas ou subsésseis; lâmina inteira ou margem denteada a serreada, membranácea a crassa. Inflorescência axilar ou terminal, cimosa ou flores solitárias; brácteas pequenas, raramente ausentes. Flores geralmente vistosas, gamopétalas, zigomorfas, raramente actinomorfas, bissexuadas, ressupinadas ou não; sépalas 5 , pouco unidas na base, às vezes até $1 / 3$ ou quase $1 / 2$ do comprimento da corola, verdes ou coloridas, inteiras a denteadas; corola tubulosa, colorida, raramente alva, às vezes gibosa na base, ou junto ao ápice, lobos subiguais ou desiguais, eretos ou patentes; estames 4, inclusos, com ou sem estaminóides inconspícuos presentes, anteras unidas, rimosas, às vezes poricidas; disco anular ou constituído de 1-5 glândulas; ovário súpero a semi-ínfero, 2-carpelar, 1locular, placentação parietal; estilete simples, estigma estomatomórfico, 2-lobado ou claviforme. Fruto baga ou cápsula seca ou carnosa, 2-valvar; sementes numerosas, geralmente elípticas, estriadas (Barroso et al. 1991; Chautems 1993; Souza \& Lorenzi 2008). 
1. Plantas sem tubérculo ou rizoma na base; corola gibosa

1. Nematanthus fornix

1'. Plantas com tubérculo na base (as vezes tubérculo e base perene) ou com rizoma soterráneo; corola tubulosa.

2. Base do caule do tipo rizoma; lâmina foliar com margem inteira; flores solitárias....

2'. Base do caule do tipo tubérculo; lâmina foliar com margem crenada, serreada ou dentada; flores em inflorescências, terminais ou axilares.

3. Caule aéreo lenhoso ou levemente suculento na parte inferior e herbáceo no ápice, perene na base; flores glabras .....

3'. Caule aéreo herbáceo, anual, flores pubérulas, pubescentes ou velutinas.

4. Planta geralmente epifítica.

5. Folhas opostas ao longo do caule; inflorescência pendente; corola vermelha

5'. Folhas condensadas em 1 (-2) verticilo(s) de 6; inflorescência ereta; corola rósea com estrias vináceas

4'. Planta geralmente rupícola ou terrícola.

6. Planta terrícola com base do caule subterrâneo; inflorescência espiciforme

6'. Planta geralmente rupícola; inflorescência axilar.

7. Caule não ramificado; lâmina foliar com face abaxial canescente-tomentosa; corola vermelho-vivo, nitidamente bilabiada.....

7'. Caule ramificado; lâmina foliar com face abaxial das folhas glanduloso-pubescente;

corola vermelho-claro ou alaranjada, tubulosa

2. Seemannia sylvatica

..7. Sinningia gigantifolia

...5. Sinningia cooperi

..6. Sinningia douglasii

4. Sinningia allagophylla

8. Sinningia magnifica

3. Sinningia aggregata

Nematanthus Schrad., Gott. Gel. Anz. 1: 718. 1821.

Nematanthus apresenta 31 espécies distribuídas na Bahia, Espírito Santo, Rio de Janeiro, São Paulo, Paraná, Santa Catarina e Rio Grande do Sul, sendo registradas cinco espécies em Minas Gerais (Chautems et al. 2005). Muitas espécies deste gênero são largamente utilizadas como ornamentais, sendo que nos Estados Unidos e na Europa estão sendo introduzidas em cultivo (Arnold 1978).

1. Nematanthus fornix (Vell.) Chautems, Candollea 39(1): 298. 1984.

Fig. $2 \mathrm{~A}$

Subarbusto epifítico ou terrícola; ramos cilíndricos glabros. Folhas às vezes anisófilas; pecíolo 0,4-1,5 cm, verde, pubérulo; lâmina ovado-elíptica, 2,8-9,6 x 1,2-2 cm, ápice agudo, margem inteira, ciliada, base cuneada, face abaxial verde-escuro, pubérula, face adaxial verde, pubérula; 3-4 pares de nervuras secundárias. Flores 1-2 por axila; eretas ou perpendiculares ao ramo, não ressupinadas; pedicelo 1,3-2 cm compr., verde-claro, pubérulo; brácteas ausentes; sépalas ca. $1,5 \times 0,7 \mathrm{~cm}$, ovadas, ápice agudo, unidas na base, verdes; corola 2,1-2,3 x 1-1,3 $\mathrm{cm}$, giba por vezes muito pronunciada, levemente projetada para a frente, vermelha, pubescente, lobos concolores eretos e patentes, face interna e externa pubescentes, tricomas glandulares; filete pubescente, 1,3-1,5 cm compr.; anteras inclusas; ovário pubescente, estilete ca. $1,5 \mathrm{~cm}$ compr., pubescentre. Fruto não visto.

Material examinado: Minas Gerais: Baependi, PESP, floresta ombrófila mista, 1.800-2.000 m.s.m., 8.XII.2012, fl., S.G. Furtado et al. 160, D.S. Santiago et al. 382 (CESJ).
Nematanthus fornix foi encontrada no PESP apenas acima dos 1800 m.s.m., em floresta ombrófila mista, como epífita, ou mais raramente, terrícola. Ocorre no Espírito Santo, Minas Gerais, Rio de Janeiro e em São Paulo, sempre nas matas de altitude de $1000 \mathrm{~m}$ até acima de 2000m (Barros et al. 2010; Araújo \& Chautems 2012). Foi coletada com flores em dezembro.

Seemannia Regel, Gartenflora 4: 183. 1855.

Seemannia é um gênero neotropical, nativo da Bolívia, Peru e Brasil e é amplamente comercializada para fins ornamentais (Wiehler 1976). Quatro espécies são reconhecidas (Roalson et al. 2005), das quais duas podem ser encontradas no Brasil, nos estados do Pará, Goiás, Mato Grosso, Mato Grosso do Sul, Minas Gerais, São Paulo, ocorrendo principalmente em áreas de campo rupestre e cerrado (Araújo \& Chautems 2012).

2. Seemannia sylvatica (Kunth) Hanst., Linnaea 29: 540. 1859.

Fig. 2 B-C

Erva terrícola, rizomatosa; caule aéreo $4-9 \mathrm{~cm}$ compr., herbáceo, ereto, esverdeado, ramificado, pubescente. Folhas opostas, levemente anisófilas, decíduas na base do caule; pecíolo 4-7 $\mathrm{mm}$ compr. pubescente; lâmina 4-12 x 0,8-2 cm, verde, discolor, estreitamente elíptica-lanceolada, membranácea, ápice acuminado, base atenuada, margem inteira, glabra, 4-5 pares de nervuras secundárias. Flor solitária, axilar, pedicelada, pedicelo $2-6 \mathrm{~cm}$ compr., vináceo, pubescente; cálice verde, sépalas 5-10 x ca. $2 \mathrm{~mm}$, lineares a estreitamente ovadas, margem 

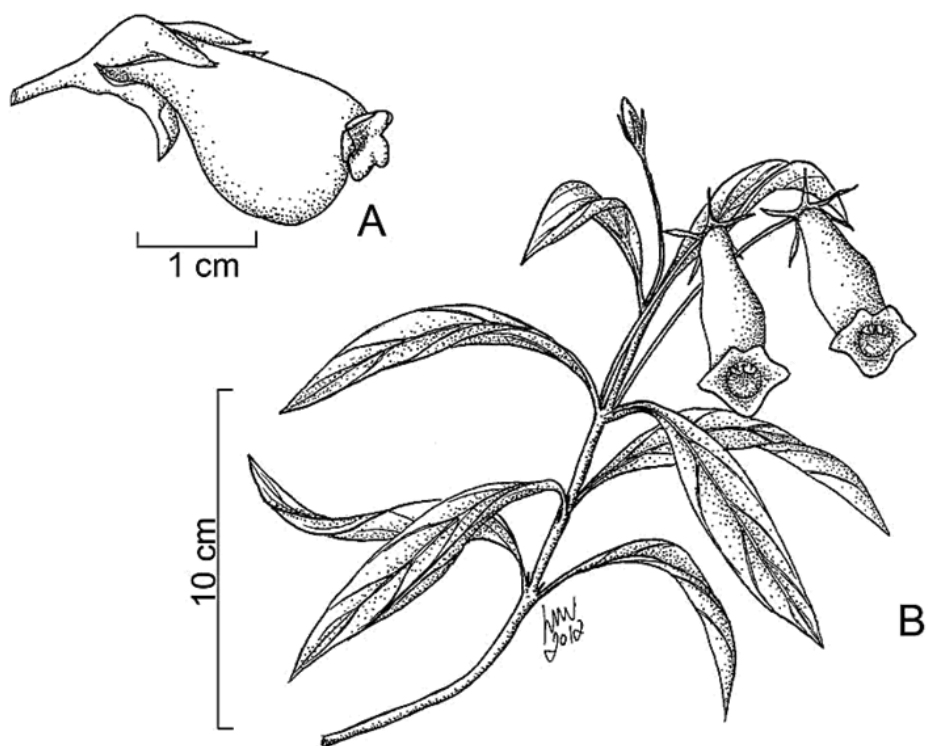

B

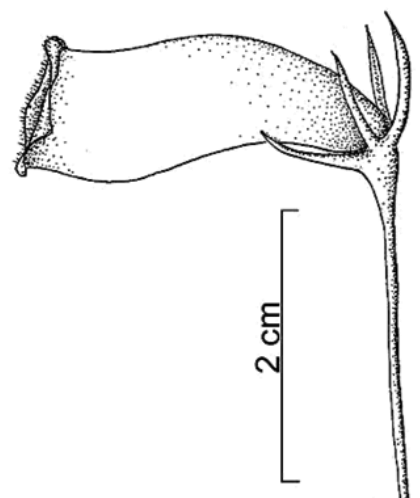

C
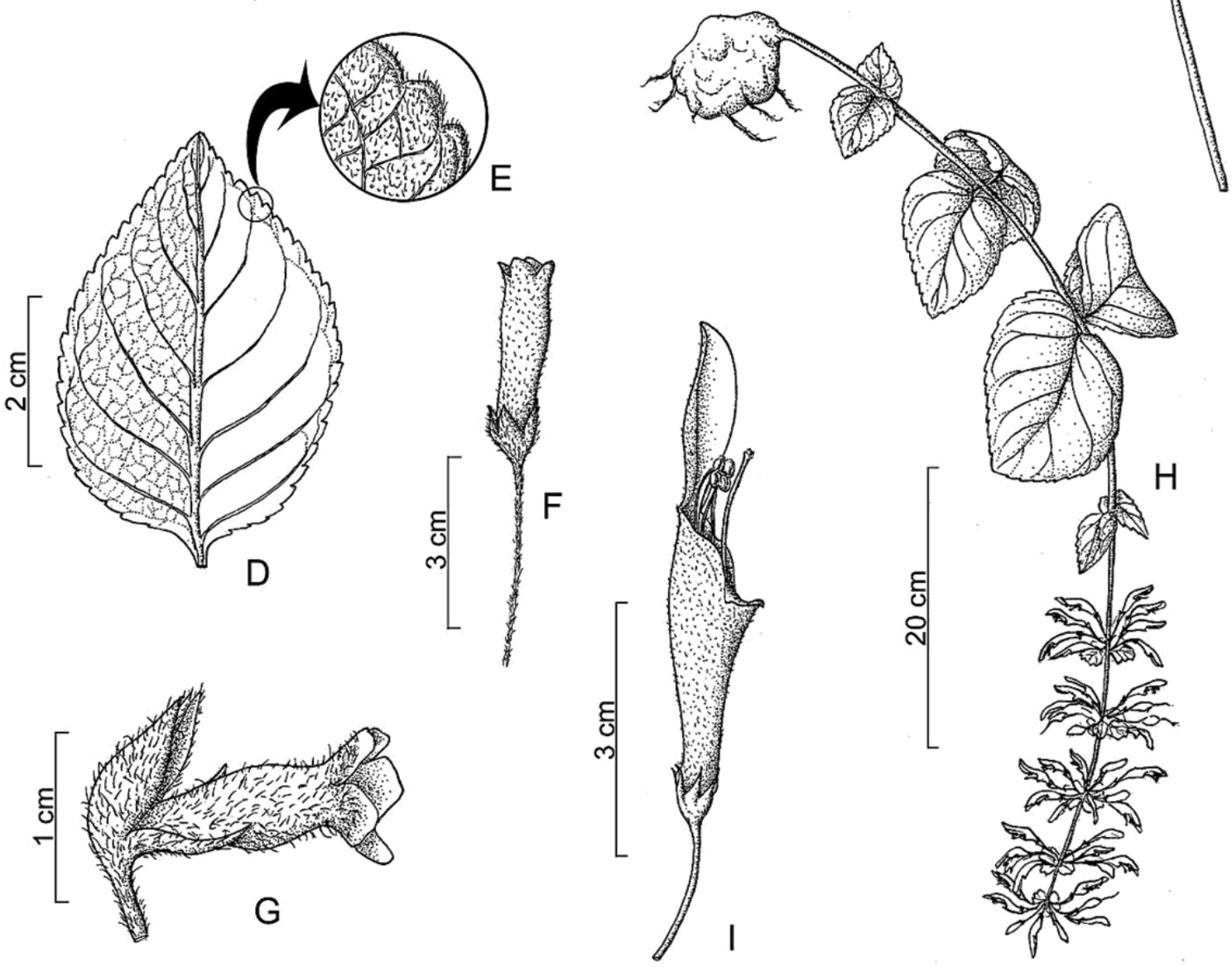

Fig. 2 - A. Nematanthus fornix, Flor, vista lateral. B-C. Seemannia sylvatica, B. Vista geral da planta; C. Flor, vista lateral. D-F. Sinningia aggregata, D. Folha, face abaxial; E. Detalhe do indumento da folha; F. Flor, vista lateral. G. Sinningia allagophylla, Flor, vista lateral. H-I. Sinningia cooperi, H. Vista geral da planta; I. Flor, vista lateral. (A. Furtado et al. 160; B-C. Pereira et al. 10; D-F. Pereira et al. 2; G. Pereira et al. 8; H-I. Pereira et al. 7). 
inteira, pubescentes; corola 1,8-2,5 x ca. $1 \mathrm{~cm}$, tubulosa, levemente ventricosa, zigomorfa, externamente vermelho-vivo, internamente alaranjada, interior da fauce amarela pintalgada de vermelho na porção ventral, densamente velutina, lobos subiguais, 2-3 x 3-4 mm, patentes, vermelhos na face interna, tricomas glandulares diminutos e esparsos cercando a abertura da fauce; estames inclusos, filetes 1,6-1,8 cm, creme, esparsamente pilosos; ovário cônico, pubescente; estilete 1,4-1,7 cm, creme; estigma 2lobado a claviforme, creme. Fruto não visto.

Material examinado: Baependi, proximidades da Cachoeira do Jujú, 27.II.2010, fl., L.C. Pereira et al. 10 (CESJ).

Seemannia sylvatica foi encontrada no PESP próximo a curso d'água, em ambiente muito úmido. Diferencia-se das demais espécies encontradas na área pelas flores solitárias de coloração vermelha na face externa da corola e amarela com pintas vináceas na face interna, sendo também a única espécie dentre as demais registradas a apresentar folhas elípticas a lanceoladas com margem inteira, além da ausência de tubérculo.

Ocorre no Equador, Peru, Bolívia, além do Paraguai (Araújo et al. 2012). No Brasil, pode ser encontrada nos estados das regiões Centro-Oeste, Sudeste (em Minas Gerais e São Paulo) e possivelmente Sul (apenas no estado do Paraná, com suspeita de planta escapada de cultivo) (Araújo \& Chautems 2012). A época de floração vai de fevereiro a novembro (Chautems \& Matsuoka 2003) e no PESP foi observada com flores no mês de fevereiro.

\section{Sinningia Nees, Ann. Sci. Nat. (Paris) 6: 297. 1825.}

Plantas rupícolas, epífitas ou terrícolas, com tubérculo perene na base; caule anual, herbáceo, raramente perene e sublenhoso na parte inferior. Folhas opostas, verticiladas ou raramente solitárias, isófilas ou fracamente anisófilas, pecíolo de comprimento variado, margem crenada, serreada ou denteada. Inflorescência no ápice do caule, em cimeira com 1 ou mais flores dispostas na axila de brácteas ou folhas, opostas ou verticiladas ou às vezes espiciforme. Flores pediceladas ou sésseis; cálice, 5-mero; corola 5-mera, com tubo campanulado a cilíndrico, intumescida na base, ligeiramente constrita próximo à base, vermelha a alaranjada ou rósea com pintas vinosas, lobos iguais, subiguais ou bilabiadas; estames 4, didínamos, inseridos na base do tubo da corola, anteras unidas, rimosa; nectário com 1-5 glândulas, às vezes as 2 adaxiais maiores separadas ou unidas; ovário semi-ínfero a súpero; estigma estomatomórfico. Fruto cápsula seca loculicida; sementes fusiformes ou elípticas, lustrosas e estriadas, sem tecido funicular espesso (Chautems \& Matsuoka 2003).

Sinningia é um gênero neotropical, sendo que só no Brasil encontra-se 67 espécies, das quais a maioria está distribuída no Domínio Atlântico nas regiões
Sudeste e Sul, sendo assim o centro de diversidade do gênero (Perret et al 2006; Araújo \& Chautems 2012).

\section{Sinningia aggregata (Ker Gawl.) Wiehler,} Selbyana 1(1): 32. 1975

Fig. 2 D-F

Erva rupícola; caule aéreo $13-18 \mathrm{~cm}$ compr., herbáceo, anual, ereto, verde, simples ou ramificado, glanduloso-pubescente; tubérculo globoso. Folhas opostas ou 3-verticiladas, levemente anisófilas; pecíolo 0,2-6 cm compr., glanduloso-pubescente; lâmina 2,5-7 x 1,5-6 cm, verde, ovada, membranácea, ápice e base subagudos, margem crenada, glanduloso-pubescente nas duas faces, 5-6 pares de nervuras secundárias. Inflorescências nas axilas das folhas, cimeiras de 3-5 flores. Flores pediceladas, pedicelo 1,2-3 cm compr., verde a avermelhado, pubescente; cálice verde, sépalas 5-9 $\times$ 2-3 mm, ovadas, margem inteira, pubescentes; corola 2,4-3,4 $\mathrm{cm}$ compr., tubulosa, levemente zigomorfa, vermelhoclaro ou alaranjada, pubescente, base intumescida com duas protuberâncias salientes no dorso, abruptamente constrita e depois progressivamente alargada, 7-9 mm de diâmetro na porção mais alargada, lobos subiguais, 1-2 x 2-3 mm, patentes, glabrescentes; estames inclusos a levemente exserto, filetes creme, 2-2,4 cm compr., anteras unidas em retângulos; estilete incluso a pouco exserto, ca. $2 \mathrm{~cm}$ compr., avermelhado. Fruto não visto.

Material examinado: Baependi: Pico do Chorão, ca. 1500 m.s.m., 7.XI.2009, fl., L.C. Pereira et al. 2 (CESJ); próximo ao Pico do Chorão, 18.IX.2009, fl., L.C. Pereira et al. 20 (CESJ); no interior da mata de Araucária, 23.XI.2012, fl., D.S. Santiago et al. 210 (CESJ).

Sinningia aggregata pode ser encontrada em afloramentos rochosos no Pico do Chorão, sendo também observada na Serra da Careta e na mata de Araucária com distribuição na face norte e sul do Parque. Pode ser reconhecida pelo odor forte das folhas (Stefanello et al. 2005).

Está distribuída desde o leste do Paraguai, ocorrendo nas regiões Norte (TO), Centro-Oeste, Sul e Sudeste do Brasil (Araújo \& Chautems 2012), floresce durante todo o ano com pico em outubro e novembro (Araújo et al. 2005). No PESP foi observada com flores nos meses de setembro a novembro.

\section{Sinningia allagophylla (Mart.) Wiehler,} Selbyana 1(1): 32. 1975

Fig. 2 G.

Erva terrícola; caule aéreo $18-43 \mathrm{~cm}$ compr., herbáceo, anual, ereto, verde a avermelhado, simples, viloso; tubérculo inteiro ou plurilobado. Folhas opostas ou 3-verticiladas, levemente anisófilas; pecíolo 1-5 mm compr., densamente lanoso; lâmina 3-7 x 1-3 cm, verde, elíptico-oblonga, cartácea, ápice obtuso, base aguda, 
margem denteada, face adaxial tomentosa, face abaxial pubescente, 4-5 pares de nervuras secundárias. Inflorescência espiciforme, séssil, $26-28 \mathrm{~cm}$ compr., geralmente compacta no início da floração, tornando-se laxiflora no final; brácteas mais curtas que as flores. Flores isoladas, na axila de 1 bráctea, pedicelo inconspícuo; cálice verde a avermelhado, sépalas com lacínias subiguais, ca. $1,2 \times 0,4 \mathrm{~cm}$, triangularessubulados, margem inteira, pubescentes; corola 1,5-1,8 $\mathrm{cm}$ compr., urceolado-tubulosa, levemente actinomorfa, alaranjada, às vezes avermelhada, pubescente, base algo gibosa dorsalmente, lobos subiguais, 4,2-5,6 x 6,7$8,2 \mathrm{~mm}$, patentes, glabrescentes; estames inclusos, filetes creme, ca. $8 \mathrm{~mm}$ compr., anteras unidas em retângulo; estilete incluso a levemente exserto, creme. Fruto ca. 1,5 cm compr., ovóide.

Material examinado: Aiuruoca, campo do Retiro dos Pedros, ca. 2000 m.s.m., 11.III.2008, fr., P.L. Viana et al. 3869 (BHCB). Baependi: 7.XI.2009, fl., L.C. Pereira et al. 3 (CESJ); 30.I.2010, fl., L.C. Pereira 4 (CESJ); 27.II.2010, fl., L.C. Pereira et al. 8 (CESJ); próximo ao Centro de Apoio ao Pesquisador, ca. 1650 m.s.m., 13.IV.2012, fl./fr., F.R.G. Salimena et al. 3416 (CESJ); Serra do Cambuí, ca. 1600 m.s.m., 14.IV.2012, fr., F.R.G. Salimena et al. 3452 (CESJ).

Sinningia allagophylla tem ampla distribuição no PESP, sendo encontrada em campos de altitude, ocorrendo entre touceiras de gramíneas, e em barrancos, na face norte do Parque, na borda da mata de Araucaria e Podocarpus. Diferencia-se das demais espécies de Sinningia do PESP por ser a única com inflorescência espiciforme, com flores alaranjadas e pequenas.

Apresenta ampla distribuição geográfica, ocorrendo no Paraguai, Uruguai, Argentina e no Brasil nas regiões Centro-Oeste, Sul e Sudeste (Araújo \& Chautems 2012). A floração ocorre de setembro a fevereiro, com pico de outubro a janeiro (Chautems \& Matsuoka 2003). No PESP foi observada com flores de novembro a abril e frutos em março e abril.

5. Sinningia cooperi (Paxton) Wiehler, Selbyana 1(1): 32. 1975.

Fig. $2 \mathrm{H}-\mathrm{I}$

Erva epífita; caule aéreo $70-80 \mathrm{~cm}$ compr., herbáceo, anual, pendente, esverdeado, simples, pubescente; com presença de tubérculo. Folhas opostas ao longo do caule, levemente anisófilas, não decíduas na base; pecíolo 0,3-6 cm compr., densamente velutino; lâmina 11-15 x 6-9 cm, verde-claro, ovado-orbicular, cartácea, ápice agudo, base obtuso-cordada, margem crenada a denteada, face adaxial pubescente a velutina, face abaxial pubescente, 7-8 pares de nervuras secundárias, brotos axilares de folhas pequenas muitas vezes presentes. Inflorescência pendente, em cimeira 4-8 flores na axila de folhas progressivamente menores no ápice, 0,8-1,8 cm compr., espatuladas, margem crenada a denteada pedúnculo inconspícuo. Flores pediceladas, pedicelo 1,5-4,5 cm compr., avermelhado, velutino; cálice inteiramente vermelho, velutino, sépalas 3-5 x 0,1-0,2 mm, conatas na base, com lobos triangulares, margem ciliada; corola 4-6 cm compr., cilíndrica, bilabiada, vermelha, velutina, base intumescida com cinco protuberâncias pequenas, em seguida levemente constrita e depois progressivamente alargada, com dois lacínios dorsais, unidos, eretos, 15-22 mm compr., 2 laterais e 1 ventral 2-3 $\mathrm{mm}$ compr., estames um pouco mais curtos que o lábio superior, filetes avermelhados, 4,6-4,9 cm compr., anteras unidas em disco; estilete tão longo quanto o lábio superior ou pouco maior no final da fase feminina, 5-5,3 cm compr., alvo. Fruto ca. 2,5 cm compr., ovóide.

Material examinado: Alagoa: ao longo do Rio do Charco, ca. 1600 m.s.m., 13.V.2008, fr., P.L. Viana et al. 3529 (BHCB). Baependi: próximo ao Centro de Apoio ao Pesquisador, ca. 1650 m.s.m., 27.II.2010, fl., L.C. Pereira et al. 7 (CESJ); às margens do Rio do Charco, ca. 1650 m.s.m., 19.V.2012, fr., S.G. Furtado \& L. Menini Neto 49 (CESJ).

Sinningia cooperi foi observada apenas como epífita sobre Podocarpus lambertii em fragmento de floresta ombrófila mista na face sul do Parque. Pode ser diferenciada de S. magnifica pelo hábito epifítico, pendente, maior porte (caule $70-80 \mathrm{~cm}$ vs. $20-40 \mathrm{~cm}$ ), inflorescência terminal e corola com lábio maior (15-22 $\mathrm{mm}$ vs. $13-14 \mathrm{~mm}$ compr.).

É uma espécie endêmica do Brasil, com ampla distribuição nos estados das regiões Sudeste e Sul (no Paraná e Santa Catarina) exclusivamente na Floresta Atlântica (Araújo \& Chautems 2012), com período de floração de dezembro a maio com pico de fevereiro a abril (Chautems \& Matsuoka 2003). No PESP foi coletada com flores em fevereiro e frutos em maio.

\section{Sinningia douglasii (Lindl.) Chautems,} Candollea 45: 382. 1990.

Fig. 3 A-B

Erva epífita; caule aéreo 9-15 cm compr., herbáceo, anual, ereto, vermelho a vináceo, simples, pubescente; com presença de tubérculo. Folhas condensadas em 1 verticilo de 6 , às vezes encimado por um segundo verticilio de 3 folhas menores de $4-10 \mathrm{~cm}$ acima do primeiro no ápice do caule, levemente anisófilas; pecíolo 2-3 cm compr., pubescente; lâmina 3-16 x 1,5-6,5 $\mathrm{cm}$, verde, lanceolada, cartácea, ápice agudo, base subcordada, margem irregularmente crenada a serreada, pubescente, 9-10 pares de nervuras secundárias. Inflorescência com raque de 6,5-15 cm compr., cimeiras de 2-3 flores em verticilo. Flores pediceladas, pedicelo $2-4 \mathrm{~cm}$, avermelhado, pubescente; cálice verde, sépalas ca. 9,5 $\mathrm{x}$ $3,1 \mathrm{~mm}$, triangulares, margem inteira, pubescente; corola 3,5-4,6 cm compr., tubulosa, rósea com estrias vináceas, pubérula, base intumescida com 5 protuberâncias pequenas, em seguida constrita, depois progressivamente alongada, lobos subiguais, 4,3-5,4 x 5,2-6 mm, eretos, pubescente; estames inclusos, filetes róseo-claros, 1,9-2,2 cm compr., anteras unidas em disco; estilete tão longo quanto os lobos da corola, 3,2-3,4 cm compr., róseo. Fruto ca. 1,7 cm compr., ovóide. 

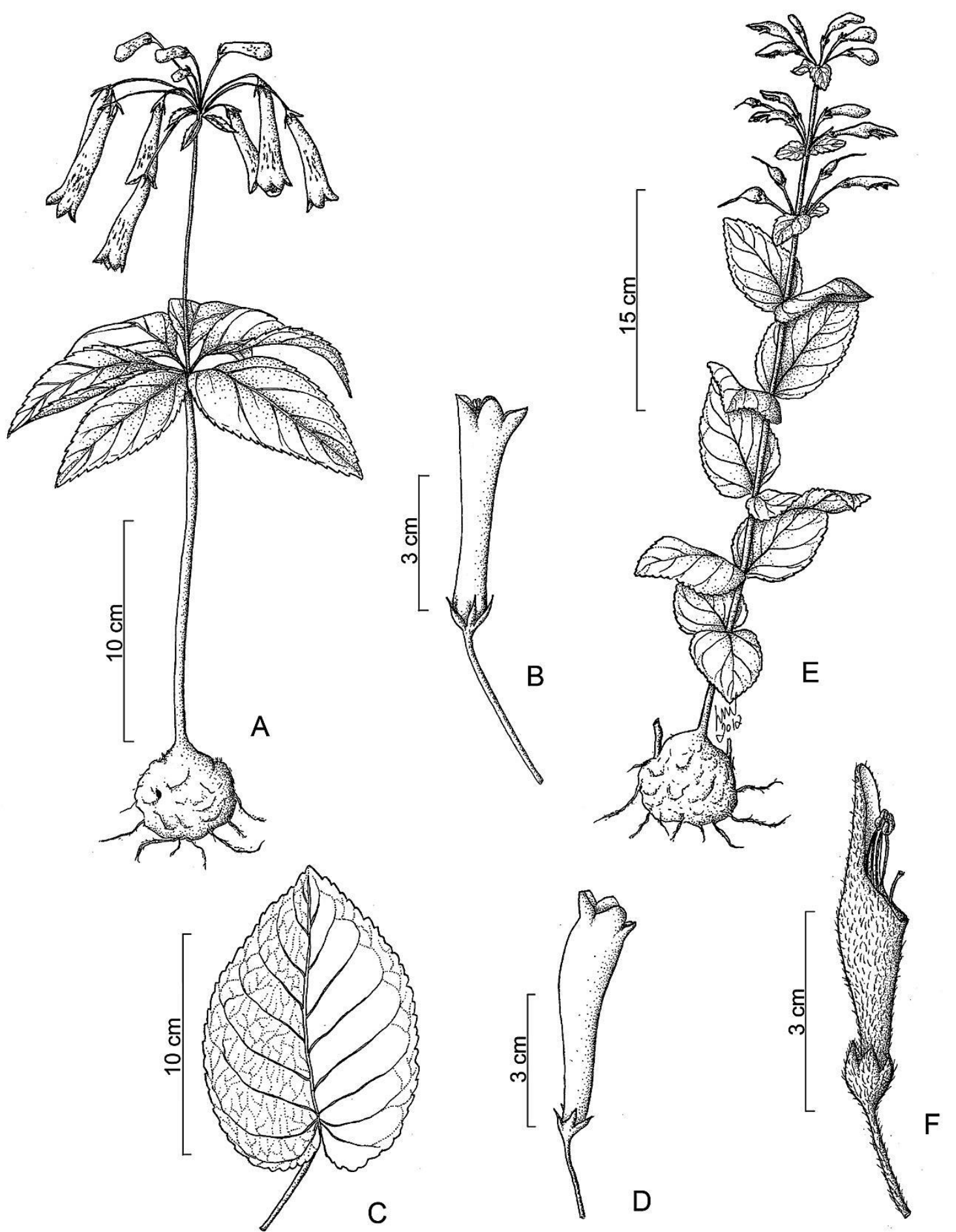

Fig. 3 - A-B. Sinningia douglasii, A. Vista geral da planta; B. Flor, vista lateral. C-D. Sinningia gigantifolia, Folha, face adaxial; D. Flor, vista lateral. E. Sinningia magnifica, E. Vista geral da planta, F. Flor, vista lateral. (A-B. Krieger et al. s.n. (CESJ 23198); C-D. Pereira et al. 1; E-F. Pereira et al. 4). 
Material examinado: Baependi: próximo ao Centro de Apoio ao Pesquisador, ca. 1650 m.s.m., 27.Il.2010 , fr., L.C. Pereira et al. 9 (CESJ); 6.XII.2012, fl., S.G. Furtado et al. 164 (CEJS).

Material adicional examinado: Minas Gerais, Parque Nacional do Caparaó, Vale Verde, 27.IX.1977, fl., L. Krieger et al. s.n. (CESJ 15051); 19.XI.1988, fl., L. Krieger et al. s.n. (CESJ 23198).

Sinningia douglasii foi observada apenas como epífita em Podocarpus lambertii, na floresta ombrófila mista da face sul do Parque, próximo ao centro de apoio ao pesquisador. Diferencia-se por ser a única espécie, dentre as coletadas, a apresentar folhas distribuídas em um verticilo no ápice do caule e pelo caule avermelhado a vináceo, além das flores róseas com estrias vináceas.

Apresenta distribuição restrita às matas úmidas das regiões Sudeste e Sul do Brasil, ocorrendo também no Noroeste da Argentina (Araújo \& Chautems 2012). A floração ocorre de agosto a março com pico de floração de setembro a dezembro (Chautems \& Matsuoka 2003). No Parque foram coletadas exemplares floridos em dezembro e em frutificação em fevereiro.

7. Sinningia gigantifolia Chautems, Candollea 45: 384. 1990.

Fig. 3 C-D

Erva rupícola; caule aéreo $4-23 \mathrm{~cm}$ compr., lenhoso ou levemente suculento na parte inferior e herbáceo no ápice, perene, ereto, avermelhado, geralmente simples, glabro a pubescente. Folhas opostas, anisófilas, decíduas na base; pecíolo 2,5-6 cm compr., velutino-pubescente; lâmina 8-17 x 7-15 cm, verde, cordada a ovada, cartácea, ápice acuminado a obtuso, base cordada, margem irregularmente denteada, face adaxial pubescente, face abaxial velutinopubescente, 7-8 pares de nervuras secundárias. Inflorescência em pseudo-racemo, terminal, ca. $20 \mathrm{~cm}$ compr., glabra, com aproximadamente 5-7 flores por ramo, axiladas por brácteas 3,9-4,3 mm compr., lanceolada a elíptica, glabras. Flores pediceladas, pedicelo 1,5-1,8 cm compr., vermelho-escuro, glabro; cálice vermelho-escuro, sépalas ca. $3 \times 4 \mathrm{~mm}$, triangular-lanceoladas, margem inteira, glabras; corola não bilabiada, 2-3,5 cm compr., tubulosa, vermelhoescuro, glabra, base levemente intumescida, sem protuberâncias salientes entre os lobos do cálice, em seguida constrita, depois progressivamente alargada, lobos subiguais, ca. $2 \times 3 \mathrm{~mm}$, patentes; estames inclusos, filetes avermelhados, 1,8-2 cm compr., glabros, anteras unidas em retângulo; estilete incluso, ca. $2 \mathrm{~cm}$ compr., avermelhado. Fruto ca. $1,5 \mathrm{~cm}$ compr., ovóide.

Material examinado: Aiuruoca: subida para o Pico do Papagaio, Pedra do Abrigo, ca. 2000 m.s.m., 12.III.2008, fr., P.L. Viana et al. 3907 (BHCB). Baependi: Cachoeira do Jujú, ca. 1500 m.s.m., 7.XI.2009, fl., L.C. Pereira et al. 1 (CESJ); próximo a Mata do Cambuí, 26.I.2013, fl., D.S. Santiago et al. 437 (CESJ).

Sinningia gigantifolia foi coletada no alto da queda da Cachoeira do Jujú, na face norte do Parque, próximo ao Pico do Papagaio e da Mata do Cambuí, respectivamente ao sul e sudeste, e observada também em afloramentos rochosos do campo de altitude no Pico do Chorão no setor norte do Parque, Serra da Careta a leste e na Serra do Canjica a oeste do Parque, no Pico do Santo Agostinho. Pode ser reconhecida pela presença de folhas grandes $e$ inflorescência totalmente glabra em comparação com as demais espécies do gênero registradas no PESP, além da base do caule aéreo perene e tubérculo que pode alcançar grandes dimensões (Arzolla et al. 2007).

É uma espécie endêmica do Brasil com distribuição restrita aos estados da Região Sudeste (Araújo \& Chautems 2012). O período de floração vai de setembro a abril (Arzolla et al. 2007). No Parque foi observada em flor nos meses de novembro a janeiro.

8. Sinningia magnifica (Otto \& A. Dietr.) Wiehler, Selbyana 1(1): 32. 1975.

Fig. 3 E-F

Erva rupícola; caule aéreo $20-40 \mathrm{~cm}$ compr., herbáceo, anual, ereto, avermelhado, não ramificado, velutino, tricomas alvos a avermelhados, com presença de tubérculo. Folhas opostas, anisófilas, não decíduas na base; pecíolo 0,3-4 cm compr., pubescente; lâmina $6-10 \times 3,8-8 \mathrm{~cm}$, verde-clara, largamente ovada, cartácea, ápice agudo a acuminado, base obtuso-cordada, margem crenada a dentada, face adaxial velutina, face abaxial canescente-tomentosa, 5-7 pares de nervuras secundárias. Inflorescência em cimeira, axilar, pedúnculo 1,2-5,5 cm compr, 2-12 flores nas axilas de folhas progressivamente menores no ápice, 7-14 mm compr. Flores pediceladas, pedicelo 1,8-4,3 cm compr., vináceo, velutino; cálice vermelho, sépalas ca. $4 \times 6 \mathrm{~mm}$, triangulares a ovado-lanceoladas, margem inteira, pubescentes; corola $3-5 \mathrm{~cm}$ compr., cilíndrica, bilabiada, vermelho-vivo com mácula vinácea interna no lobo ventral, pubescente a velutina, base intumescida com cinco protuberâncias pequenas, em seguida abruptamente constrita, depois progressivamente alargada, com dois lacínios dorsais, unidos, eretos, $13-14 \times 6-8 \mathrm{~mm}$, dois laterais ca. $2 \times 6$ $7 \mathrm{~mm}$, um ventral 1-2 x 4-5 mm; estames um pouco mais curtos que o lobo superior, filetes avermelhados, ca. 3,2 cm compr., esparsamente pilosos, anteras unidas em disco; estilete tão longo quanto o lábio superior ou pouco maior no final da fase feminina, ca. $4,2 \mathrm{~cm}$ compr., alvo. Fruto não visto.

Material examinado: Aiuruoca: campo do Retiro dos Pedros, ca. 2000 m.s.m., 11.III.2008, fl., P.L. Viana et al. 3882 (BHCB). Baependi: Cachoeira do Jujú, ca. 1500 m.s.m., 30.I.2010, fl., L.C. Pereira et al. 4 (CESJ). 
Sinningia magnifica foi encontrada em afloramentos e paredões rochosos próximos a Cachoeira do Jujú no lado norte do Parque e na Serra da Careta a leste, apresentando grande variação no porte da planta e número de flores. Diferencia-se de $S$. cooperi pelo caule ereto, flores vermelho-escuras e por não ser epífita.

É uma espécie endêmica do Brasil, ocorrendo nos campos rupestres nos estados da Região Sudeste (Araújo \& Chautems 2012). Apresenta período de floração entre os meses de fevereiro a maio (Chautems \& Matsuoka 2003), embora no PESP tenha sido coletado com flores em janeiro e março.

\section{Agradecimentos}

À Dra. Fátima Regina Gonçalves Salimena, por ter me recebido no Herbário Lepoldo Krieger da Universidade Federal de Juiz de Fora; ao companheiro de coleta André Luiz Carvalho Pereira, e ao Instituto Estadual de Florestas de Minas Gerais, pela licença de coleta e apoio logístico no PESP.

\section{Referências}

ALVES, R.J.V. \& KOLBEK, J. 2009. Summit vascular flora of Serra de São José, Minas Gerais, Brazil. Check List 5(1): 35-73.

ARNOLD, P. 1978. The Gesneriad Register - Nematanthus, check-list of names with descriptions of cultivated plants. Gloxinian 28(5): 1-8.

ARAÚJO, A.O. \& CHAUTEMS, A. 2012. Gesneriaceae In Lista de Espécies da Flora do Brasil. Jardim Botânico do Rio de Janeiro. (http://floradobrasil.jbrj. gov.br/2012/FB007879)

ARAÚJO, A.O., CHAUTEMS, A. \& SOUZA, V.C. 2004. Flora da Serra do Cipó, Minas Gerais: Gesneriaceae. Bol. Bot. Univ. São Paulo 22: 43-51.

ARAÚJO, A.O., SOUZA, V.C. \& CHAUTEMS, A. 2005. Gesneriaceae da Cadeia do Espinhaço de Minas Gerais. Revista Brasil. Bot. 28(1): 109-135.

ARAUJO, A. O., SOUZA, V.C. \& CHAUTEMS, A. 2012. Estudos taxonômicos em Gloxinieae (Gesneriaceae) notas nomenclaturais. Acta Bot. Bras. 26(4): 891-900.

ARZOLLA, F.A.R.D.P., PAULA, G.C.R., CHAUTEMS, A.P. \& SHEPHERD, G.J. 2007. O primeiro registro de Sinningia gigantifolia Chautems (Gesneriaceae) no estado de São Paulo. Biota Neotropica 7: 375-377.

BARROS, M.J.G., MANSANO, V.F., CHAUTEMS, A. 2010. Comparação florística e taxonômica da família Gesneriaceae no Parque Nacional do Itatiaia, Brasil. Hoehnea 37(1): 131-145.

BARROSO, G.M., PEIXOTO, A.L., ICHASO, C.L.F., COSTA, C.G., GUIMARÃES, E.F. \& LIMA, H.C. 1991. Sistemática de Angiospermas do Brasil. Vol. 3. 2ª ed. Universidade Federal de Viçosa. Viçosa.
BLASER, J.G., EITERER, M., SALIMENA, F.R.G. \& CHAUTEMS, A. 2011. Gesneriaceae do Parque Estadual do Ibitipoca, Minas Gerais, Brasil. Bol. Bot. Univ. São Paulo 29: 1-12.

BURTT, B.L \& WIEHLER, H.B. 1995. Classification of the family Gesneriaceae. Gesneriana 1: 1-4.

CHAUTEMS, A. 1993. Gesneriaceae. In R. Spichiger \& L. Ramella (eds) Flora del Paraguay - 22. Missouri Botanical Garden. Missouri.

CHAUTEMS, A.; LOPES, T.C.C; PEIXOTO, M. \& ROSSINI, J. 2005. Five new species of Nematanthus Schrad. (Gesneriaceae) from eastern Brazil and a revised key to the genus. Selbyana 25(2): 210-224.

CHAUTEMS, A. (Coord.), MATSUOKA, C.Y.K. 2003. Gesneriaceae. In M.G.L. Wanderley, G.J. Shepherd; A.M. Giulietti, T.S. Melhem \& M. Kirizawa (eds.) Flora fanerogâmica do Estado de São Paulo. Instituto de Botânica de São Paulo. São Paulo, vol. 3, p. 75-103.

CHAUTEMS, A. 2007. Gesneriaceae. In M. Simonelli \& C.N. Fraga (orgs) Espécies da flora ameaçadas de extinção no estado do Espírito Santo. IPEMA. Vitória.

COSTA, J.P.O. 1994. Aiuruoca - Matutu e Pedra do Papagaio: um estudo de conservação do ambiente natural e cultural. EDUSP. São Paulo.

EXECUTIVO/MG. 1998. Decreto oㅜ 39793, de 5 de agosto de 1998. Criação do Parque Estadual da Serra do Papagaio, Diário do Executivo do Estado de Minas Gerais, Belo Horizonte.

FIDALGO, O. \& BONONI, V.L.R. 1989. Técnicas de coleta, preservação e herborização de material botânico. Instituto de Botânica de São Paulo. São Paulo.

GONÇALVES, Y.K. 2003. Perspectivas do desenvolvimento turístico em áreas rurais: o caso das Terras Altas da Mantiqueira (MG). Dissertação de Mestrado. Universidade Estadual de Campinas, Campinas.

IEF/MG - Instituto Estadual de Florestas. 2010. Parque Estadual da Serra do Papagaio. (http://www.ief.mg. gov.br/index.php?option=com_content\&task=view\&id=21 1\&ltemid=37).

LEONI, L.S. \& CHAUTEMS, A. 2004. Flora Fanerogâmica do Parque Nacional do Caparaó: Gesneriaceae. Pabstia 15: 1-11.

LEONI, L.S., ROCHA, M.J.R. \& CHAUTEMS, A. 2005. A Flora Fanerogâmica do Parque Estadual da Serra do Brigadeiro: Gesneriaceae. Pabstia 16: 1-12.

PERRET, M., CHAUTEMS, A. \& SPICHIGER, R. 2006. Dispersal-vicariance analyses in the tribe Sinningieae (Gesneriaceae): a clue to understanding biogeographical history of the Brazilian Atlantic Forest. Ann. Missouri Bot. Gard. 93: 340-358.

REZENDE, M.G. 2010. Flora da Serra da Pedra Branca, Caldas, Minas Gerais, Brasil. Dissertação de Mestrado. Universidade Federal de Juiz de Fora, Juiz de Fora.

ROALSON, E.H.; BOGGAN, J.K. \& SKOG, L.E. 2005. Reorganization of tribal and generic boundaries in the Gloxinieae (Gesneriaceae: Gesnerioideae) and the description of a new tribe in the Gesnerioideae, Sphaerorrhizeae. Selbyana 25(2): 225-238. 
SILVA, L.V.C., VIANA, P.L. \& MOTA, N.F.O. 2008. Plano de Manejo do Parque Estadual da Serra do Papagaio, Minas Gerais, Brasil. Instituto Estadual de Florestas, Belo Horizonte.

SOUZA, V.C. \& LORENZI, H. 2008. Botânica Sistemática - Guia ilustrado para identificação das famílias de Fanerógamas e exóticas do Brasil, baseado em APG II. $2^{\text {a }}$ ed. Instituto Plantarum de Estudos da Flora. Nova Odessa.

STEFANELLO, M.E.A., CERVI, A.C. \& WISNIEVSKI JR., A. 2005. Composição do óleo essencial de Sinningia aggregata. Revista Bras. Farmacog. 15: 331-333.
THIERS, B. 2012 [continuously updated]. Index Herbariorum: A global directory of public herbaria and associated staff. New York Botanical Garden's Virtual Herbarium. (http://sweetgum.nybg.org/ih/)

WEBER, A. 2004. Gesneriaceae. In K. Kubitzki (ed) The families and genera of vascular plants. Heidelberg Springer. Berlin, vol. 7, p. 63-158.

WIEHLER, H. 1976. A report on the classification of Achimenes, Eucodonia, Seemannia, Goyazia, and Anetanthus (Gesneriaceae). Selbyana 1:374-404. 